\title{
Research on Short-term Aging of Lignin Modified Asphalt
}

\author{
Xin $\mathrm{Fu}^{1}$, Mao $\mathrm{He}^{2}$ and Yuancai Liu ${ }^{1 *}$ \\ ${ }^{1}$ College of Civil Engineering, Southwest Forestry University, Kunming, Yunnan, 650224, China \\ ${ }^{2}$ College of Civil Engineering, Southwest Forestry University, Kunming, Yunnan, 650224, China
}

\begin{abstract}
In order to study the micro-aging mechanism of lignin-modified asphalt, different asphalt samples were prepared with lignin content of $0 \%$ and $12 \%$ by mass. The conventional asphalt index test and high-temperature dynamic shear rheological test were used to analyze the different asphalt samples. The change law of the performance of modified lignin modified asphalt with thermal oxygen aging time. The results show that adding appropriate amount of lignin to each asphalt will increase the penetration and ductility of the base asphalt, reduce the softening point, and significantly improve the high-temperature stability; comparative analysis before and after DSR aging, the complex shear modulus $G^{*}$ increases and The decrease of phase angle $\delta$ indicates that lignin can improve the high-temperature rheological properties of asphalt.
\end{abstract}

\section{Introduction}

With the rapid construction of expressways, petroleum asphalt is more and more widely used as road maintenance materials. However, due to the increasingly serious effects of vehicle axle load and natural damage and aging, ordinary road asphalt often exhibits shortcomings such as low temperature and easy brittleness, high temperature and easy flow, and poor anti-aging effects, which are difficult to meet its normal road performance. Therefore, it is necessary to mix appropriate modifiers into the base asphalt to modify it physically and chemically to meet the requirements of different situations. Lignin is a natural aromatic renewable biomass material. Its content on the earth is second only to cellulose. Together with cellulose and hemicellulose, it forms the main chemical component of the plant skeleton. It can often replace chemicals to realize an environmentally friendly chemical and chemical system [1]. Lignin itself belongs to the threedimensional network macromolecular structure formed by the connection of phenylpropane monomers through ether bonds. It can be physically blended with other polymer materials [2], and it can also be incorporated into the material to improve the comprehensiveness of the material through physical and chemical reactions Performance [3], reduce the cost of industrial manufacturing, and achieve certain ecological and economic benefits [4-5]. Based on the characteristics of lignin in the industrial field, domestic and foreign scholars have made significant research results in lignin modified asphalt. There have been many studies on the performance of lignin-modified asphalt before and after aging, but most of them focus on the changes in the macroscopic properties of base asphalt and modified asphalt, and there is a lack of exploration of a certain amount of lignin based on the changes of different asphalts before and after short-term aging. Therefore, it is necessary to conduct a more in-depth study on the short-term aging of $12 \%$ lignin-modified asphalt in order to increase the service life of road asphalt and provide a theoretical basis for the effective utilization of biomass resources in the engineering field.

\section{Materials and Methods}

\subsection{Test materials}

The base asphalts used in the test are South Korea SK Shell asphalt and American shell Shell asphalt. According to the highway engineering asphalt and asphalt mixture test regulations (JTGE20-2011), the performance test of each base asphalt is carried out. The results are shown in Table 1. Lignin is provided by a certain chemical company in the city, and its indicators are shown in Table 2.

Table 1. Main Technical indexes of lignin

\begin{tabular}{|c|c|}
\hline Technical index & Content \\
\hline $\mathrm{PH}$ & $6.9 \sim 8.0$ \\
\hline Exterior color & Brown powder \\
\hline Ash $/ \%$ & 1.2 \\
\hline Sugar content $/ \%$ & $1.1 \sim 2.9$ \\
\hline Lignin content $/ \%$ & $85.2 \sim 90.3$ \\
\hline
\end{tabular}

Table 2. Performance lindex of base asphalt

\begin{tabular}{|c|c|c|}
\hline Pilot projects & SK test value & shell test value \\
\hline Penetration $\left(25^{\circ} \mathrm{C} / 0.1 \mathrm{~mm}\right)$ & 64.3 & 52.7 \\
\hline Softening point $\left({ }^{\circ} \mathrm{C}\right)$ & 46.8 & 45.2 \\
\hline
\end{tabular}

\footnotetext{
*Corresponding author's E-mail: 1121702038@qq.com
} 


\begin{tabular}{|c|c|c|}
\hline Ductility $\left(15^{\circ} \mathrm{C} / \mathrm{cm}\right)$ & $>150$ & $>150$ \\
\hline Penetration after aging & 50.7 & 36.9 \\
\hline Softening point after aging & 50.2 & 51.7 \\
\hline Ductility after aging & 133.1 & 108.2 \\
\hline
\end{tabular}

\subsection{Test methods}

SK-0 and shell -0 are used as base asphalt (without adding lignin), and $12 \%$ lignin is added to prepare modified asphalt, which is recorded as SK-12 and shell12 for subsequent tests. The high-speed shearing dispersing emulsifier produced by Shanghai Weiyu Co., Ltd. was used to prepare the lignin modified asphalt. Put the two shell base asphalts in an oven at $120^{\circ} \mathrm{C}$ for 1 hour at a constant temperature, and heat them to a fluid state, and then shear and mix 12\% lignin and base asphalt at $150^{\circ} \mathrm{C}$ for 1 hour $(5000 \mathrm{r} / \mathrm{min})$. After shearing and mixing are sufficient, put the mixture in a constant temperature oven at a temperature of $120^{\circ} \mathrm{C}$ for 1 hour, which is the prepared lignin modified asphalt sample.

\subsection{Analytical methods}

\subsubsection{Routine index test}

The conventional performance measurement of penetration, softening point and ductility of base asphalt and lignin modified asphalt were carried out according to the methods described in GB/T4507-2010, GB/T45092010, and GB/T4508-2010, respectively.

\subsubsection{Dynamic Shear Rheology Test (DSR)}

The dynamic shear rheological test of this test is carried out in accordance with the T0628-2011 regulation in the "Test Regulations for Highway Engineering Asphalt and Asphalt Mixtures" (JTG E20-2011). Using the CVOR150 dynamic shear rheological tester produced by Bohlin, USA, the two base asphalts before and after TFOT aging and $12 \%$ lignin were modified at $60^{\circ} \mathrm{C}$, $66^{\circ} \mathrm{C}$ and $72^{\circ} \mathrm{C}$ respectively. Asphalt is tested.

\section{Results and analysis}

\subsection{Comparison of conventional performance}

From Figure 1 and Figure 2, it is known that the residual penetration ratio reflects the influence of asphalt aging on penetration. The larger the ratio, the better the aging resistance. The value-added of the melting point is to evaluate the impact of asphalt aging on the softening point. The larger the value-added, the more beneficial it is. The residual penetration ratios of SK and shell asphalt samples both increase with the addition of lignin, showing a certain regularity. When the lignin content increased from $0 \%$ to $12 \%$, the residual penetration ratio of SK and shell modified asphalt increased by $8.9 \%$ and $5.9 \%$, and the softening point increment decreased by 0.7 and 3.4, respectively. This shows that the incorporation of lignin has an impact on the aging resistance of the two base asphalts. 12\% lignin can effectively improve the short-term thermal oxidative aging performance of the asphalt, but its degree often depends on the effect of lignin on different base asphalts. The selective size is gone.

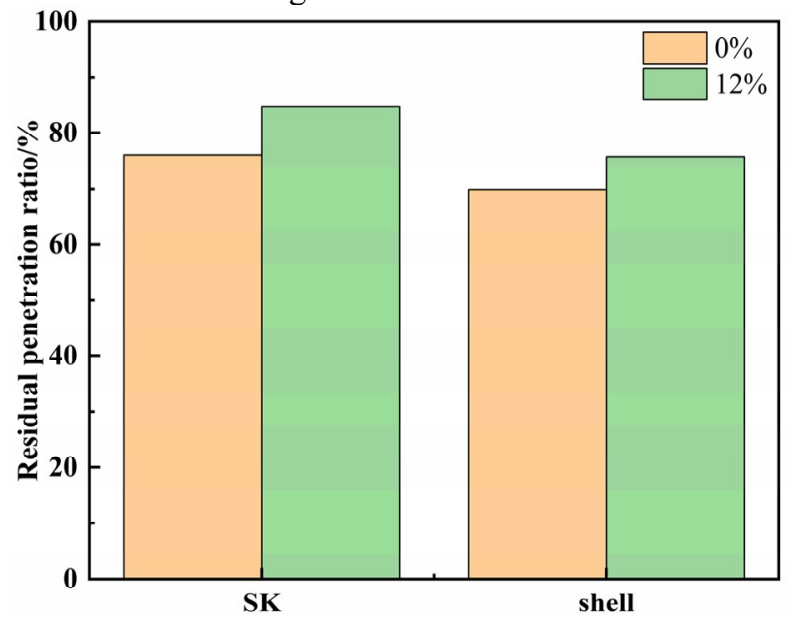

Figure 1. Comparison of residual penetration ratio of different modified bitumen

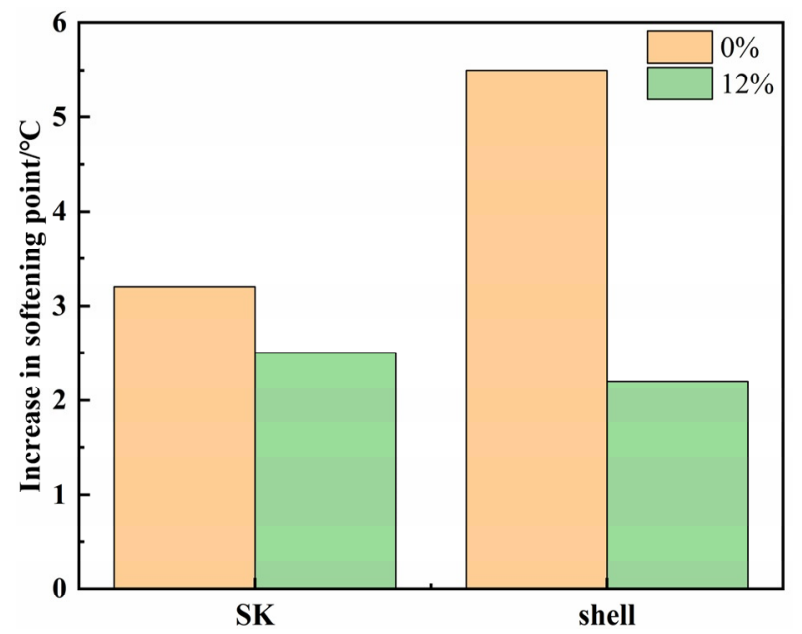

Figure 2. Comparison of softening points of different modified bitumen

Table 3 and Table 4 are the comparison of the mass fraction of lignin in SK and shell base asphalts against the conventional properties of asphalt penetration, softening point and ductility. It can be seen from Table 3 and Table 4: Compared with the base asphalt, the penetration of $12 \%$ lignin is reduced in the two modified asphalts. The decrease in penetration indicates that the more viscous asphalt is after aging. The stronger the resistance to deformation. Compared with the same kind of base asphalt before aging, the penetration index of SK-12 decreased by $13.79 \%$ compared with SK-0, and the penetration index of shell-12 decreased by $9.78 \%$ compared with shell-0. Lignin showed a downward trend in penetration in both modified asphalts, and the decline 
Table 3. Effect of lignin content on properties of SK before and after aging

\begin{tabular}{|c|c|c|c|c|c|c|c|c|c|}
\hline \multirow{2}{*}{$\begin{array}{c}\text { Lignin } \\
\text { Dosage } \\
/ \%\end{array}$} & \multicolumn{2}{|c|}{ Penetration at $25^{\circ} \mathrm{C} / 0.1 \mathrm{~mm}$} & \multicolumn{3}{c|}{ Softening point $/{ }^{\circ} \mathrm{C}$} & \multicolumn{3}{c|}{ Ductility at $15^{\circ} \mathrm{C} / \mathrm{cm}$} \\
\cline { 2 - 9 } & $\begin{array}{c}\text { Before } \\
\text { aging }\end{array}$ & $\begin{array}{c}\text { After } \\
\text { aging }\end{array}$ & $\begin{array}{c}\text { Residual } \\
\text { penetration } \\
\text { ratio/\% }\end{array}$ & $\begin{array}{c}\text { Before } \\
\text { aging }\end{array}$ & $\begin{array}{c}\text { After } \\
\text { aging }\end{array}$ & $\begin{array}{c}\text { Increase in } \\
\text { softening } \\
\text { point } /{ }^{\circ} \mathrm{C}\end{array}$ & $\begin{array}{c}\text { Before } \\
\text { aging }\end{array}$ & $\begin{array}{c}\text { After } \\
\text { aging }\end{array}$ & $\begin{array}{c}\text { Residual } \\
\text { ductility } \\
\text { ratio/\% } \%\end{array}$ \\
\hline 0 & 66.3 & 51.4 & 76.1 & 46.7 & 49.9 & 3.2 & 149.8 & 133.0 & 88.8 \\
\hline 12 & 50.9 & 43.9 & 84.7 & 48.8 & 51.3 & 2.5 & 45.3 & 23.7 & 52.3 \\
\hline
\end{tabular}

Table 4. Effect of lignin content on properties of shell before and after aging

\begin{tabular}{|c|c|c|c|c|c|c|c|c|c|}
\hline \multirow{2}{*}{$\begin{array}{c}\text { Lignin } \\
\begin{array}{c}\text { Dosage } \\
/ \%\end{array}\end{array}$} & \multicolumn{3}{|c|}{ Penetration at $25^{\circ} \mathrm{C} / 0.1 \mathrm{~mm}$} & \multicolumn{3}{c|}{ Softening point $/{ }^{\circ} \mathrm{C}$} & \multicolumn{3}{c|}{ Ductility at $15^{\circ} \mathrm{C} / \mathrm{cm}$} \\
\cline { 2 - 9 } & aging & $\begin{array}{c}\text { After } \\
\text { aging }\end{array}$ & $\begin{array}{c}\text { Residual } \\
\text { penetration } \\
\text { ratio/\% }\end{array}$ & $\begin{array}{c}\text { Before } \\
\text { aging }\end{array}$ & $\begin{array}{c}\text { After } \\
\text { aging }\end{array}$ & $\begin{array}{c}\text { Increase in } \\
\text { softening } \\
\text { point } /{ }^{\circ} \mathrm{C}\end{array}$ & $\begin{array}{c}\text { Before } \\
\text { aging }\end{array}$ & $\begin{array}{c}\text { After } \\
\text { aging }\end{array}$ & $\begin{array}{c}\text { Residual } \\
\text { ductility } \\
\text { ratio/\% } / \%\end{array}$ \\
\hline 0 & 52.8 & 36.9 & 69.9 & 46.0 & 51.5 & 5.5 & 150.1 & 108.4 & 72.3 \\
\hline 12 & 43.3 & 32.8 & 75.8 & 50.1 & 52.4 & 2.2 & 46.6 & 26.9 & 57.5 \\
\hline
\end{tabular}

in shell was better than that of SK. It shows that adding a certain amount of lignin to the base asphalt can improve the viscosity of the asphalt, and there are also certain performance differences between different brands of base asphalt. The softening point of the two lignin modified asphalts has been increased, and the increase of the softening point can effectively improve the high temperature stability of the asphalt. For the same type of base asphalt, the softening point of the $12 \%$ ligninmodified asphalt before and after aging is higher than that of the base asphalt, and the softening point of the two asphalts has relatively the same change range. The base asphalt with lignin content has less ductility before and after aging than the base asphalt. The ductility values of SK and shell are small after adding lignin. The ductility values of the two asphalts before aging have no obvious difference when there is no shear and no development, but the matrix asphalt and lignin content after shear development are 12 There are some gaps in $\%$. Under the same preparation process conditions, the incorporation of lignin makes the ductility of the asphalt less than that of the base asphalt without lignin. The decrease in the overall ductility of the lignin-modified asphalt may be due to the addition of lignin. The related bitumen content in the volume is reduced, thereby reducing the anti-deformation performance of the bitumen.

\subsection{High temperature rheological performance analysis}

The dynamic shear rheological test (DSR) was used to study the rheological properties of two lignin-modified asphalt before and after aging. DSR can record the changes of asphalt complex shear modulus $\mathrm{G}^{*}$ and phase angle $\delta$ at different temperatures (the test temperature is $60,66,72^{\circ} \mathrm{C}$ ), which characterizes the "soft and hard" and fluidity of asphalt at these three temperatures. The larger the $\mathrm{G}^{*}$ or the smaller the $\delta$, the harder the bitumen is and it is not easy to flow. On the contrary, the softer the bitumen, the easier it is to flow. The $\mathrm{G}^{*}$ and $\delta$ test results of the two asphalt samples at three test temperatures after short-term aging are shown in Figure 3 to Figure 6.

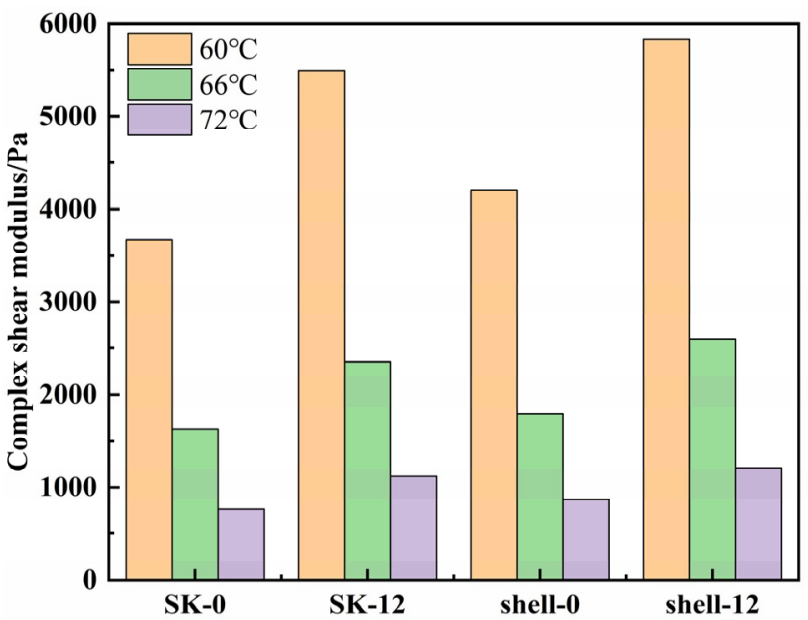

Figure 3. Complex shear modulus before aging

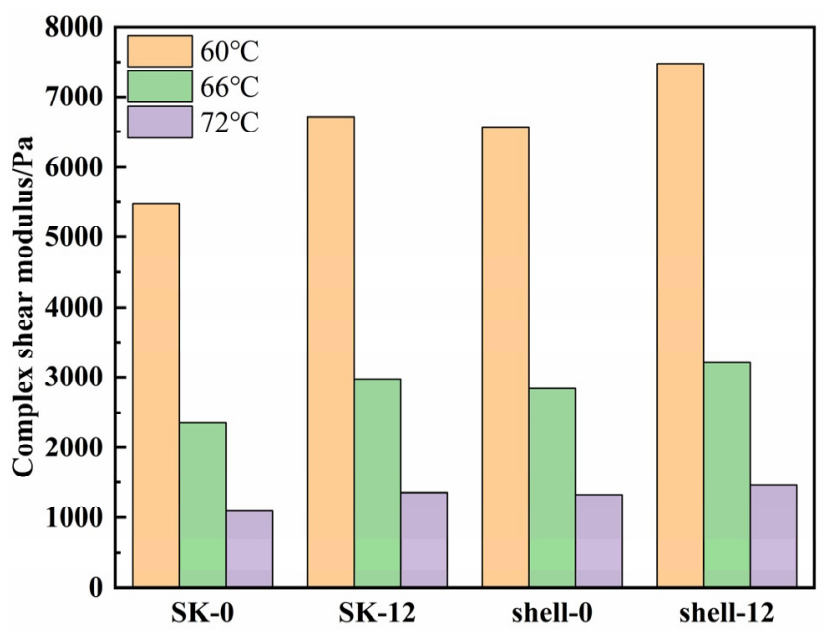

Figure 4. Complex shear modulus after aging 


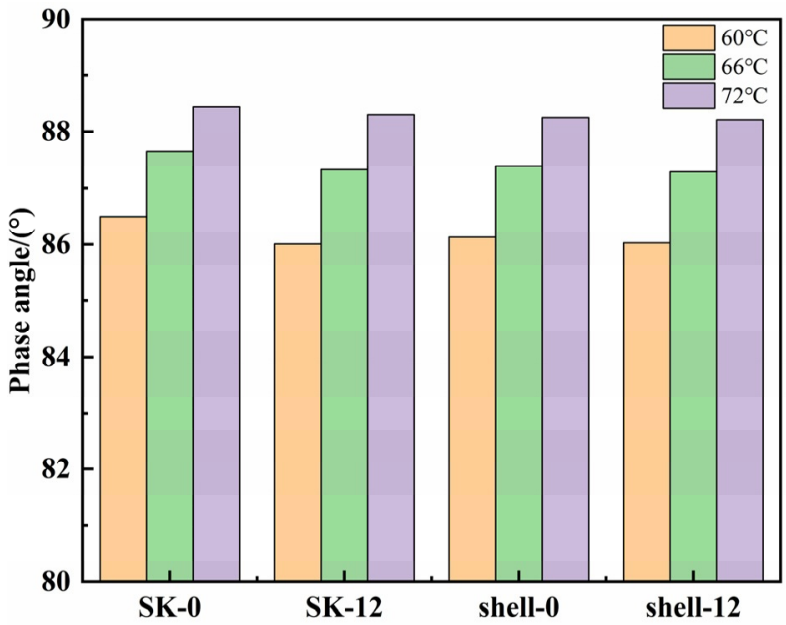

Figure 5. Phase angle before aging

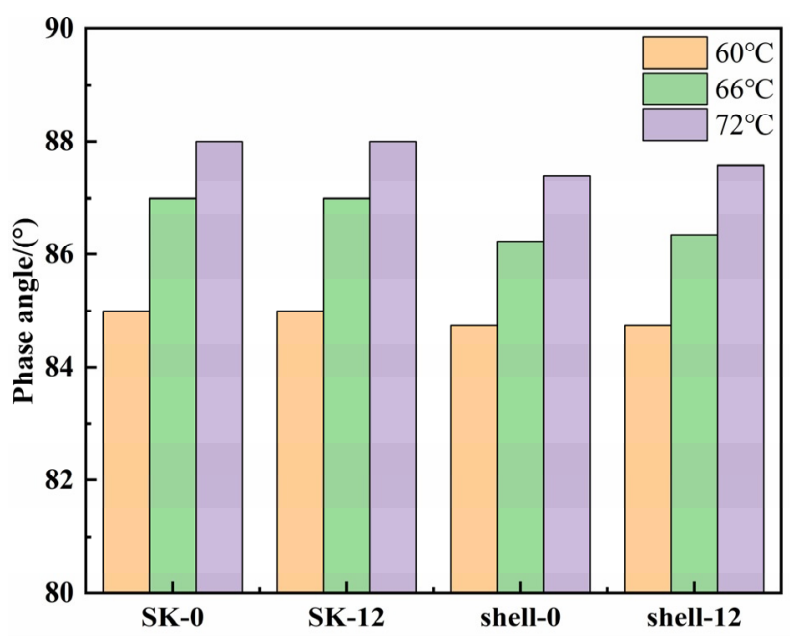

Figure 6. Phase angle after aging

It can be seen from the figure that before aging, $12 \%$ lignin will increase the complex shear modulus of both SK and shell asphalts and improve the elastic properties and deformation resistance of asphalt materials. As the temperature of the same kind of asphalt increases before and after aging, the complex shear modulus shows a downward trend. The decrease of $\mathrm{G}^{*}$ indicates that the closer the asphalt is to the elastomer, the better the hightemperature rheological properties. The phase angle $\delta$ of the two base asphalts and the $12 \%$ lignin-modified asphalt showed a downward trend before and after aging, which confirmed that all asphalt samples were subjected to short-term thermal oxidative aging.

\section{Conclusions}

1) The penetration and ductility of the two modified asphalts with $12 \%$ lignin are significantly reduced, and the softening point is increased. Lignin can effectively improve the short-term thermal oxidative aging performance of asphalt.

2) Lignin can show a certain positive resistance in the service of asphalt roads in the future, which is conducive to the effective use of agricultural and forestry wastes.

\section{References}

1. Yan, L.F., Zhu, Q.S. Chemistry and chemical engineering with biomass as raw materials [J]., CIESC Journal.,55 (12): 1938-1943. (2004)

2. Wu, W.J., Infrared spectroscopy analysis of ligninmodified asphalt[J]., Journal of Jiangsu University (Natural Science Edition)., 40 (1): 120-124. (2019)

3. Li, Z.Z., Research on renewable biomass resourceslignin [J]., Nanjing Forestry University (Natural Science Edition).,36 (1): 1-7. (2012)

4. DUVAL A, LAWOKO M., review on lignin-based polymeric, micro and nano-structured materials [J]., Reactive \& Functional Polymers., (85): 78-96. (2014)

5. Yang, X.H., The application of lignin in the synthesis of polyurethane[J]., Forestry Chemistry and Industry, 30(3): 115-120. (2010) 